\title{
¿Cómo combinar la E mayúscula y la I mayúscula? Psicoanalistas y escritores tras el enigma de la doble
} entropía

How to Combine Capital E and Capital I? Psychoanalysts and Writers in pursuit of double entropy enigma

\section{Jorge Manzi Cembrano}

Universidad de São Paulo

Este escrito sugerirá que el cruce entre entropía cibernética (pérdida de información) y entropía termodinámica (pérdida de energía y desorganización de la materia) puede entenderse como enigma clave común a la teoría psicoanalítica (desde la 'pulsión de muerte' freudiana) y a aquella literatura contemporánea que afirma a la repetición como nueva dominante de la experiencia. La argumentación partirá discutiendo el giro cibernético propuesto por Jacques Lacan en el Libro 2 de su Seminario y terminará por presentar el modo en que dos autores contemporáneos -William Burroughs y Juan Carlos Onetti- trataron con el enigma de la 'doble entropía'.

Palabras clave: entropía, psicoanálisis, William Burroughs, Juan Carlos Onetti.

This article argues that the intersection between cybernetic entropy (loss of information) and thermodynamic entropy (loss of energy and disorganization of matter) could be considered a key enigma common both to psychoanalytic theory (since the Freudian 'death instinct') and contemporary literature inasmuch as it has been concerned with repetition as a new dominant of experience. The argument will begin by discussing the cybernetic turn proposed by Jacques Lacan in the Book 2 of his Seminar and will end by presenting the terms in which two contemporary authors -William Burrough and Juan Carlos Onetti- dealt with the 'double entropy' enigma.

Keywords: entropy, psychoanalysis, William Burroughs, Juan Carlos Onetti. 
Referirse al espíritu del idealismo alemán en términos de 'aparato psíquico homeostático' fue uno de los gestos que inauguraron una difícil posición poshumanista para el psicoanálisis en el campo de las ciencias humanas. A partir de las neurosis postraumáticas de la Primera Guerra Mundial Freud puso en crisis su propio modelo de aparato al considerar la lógica repetitiva de cierto tipo de huellas mnémicas. A las escenas edípicas de seducción, y a voces paternas excesivas, la guerra sumaba bombardeos, ametralladoras y detonaciones. Un nuevo repertorio de recuerdos traumáticos que no serían origen de ningún relato fluido ni placentero: el retorno de explosiones que despertaban de golpe al veterano de guerra eran algo muy ajeno a las magdalenas de Proust. Y cuando el veterano resultaba ser un escritor-como Louis Ferdinand Céline y su Viaje al fin de la noche (1932) - ya no se percibiría el mismo entusiasmo al ir en busca de las huellas mnémicas. Al respecto, el psicoanálisis sería pionero en advertir la necesidad de una oposición conceptual fuerte entre 'reminiscencia' (aquella articulación fluida gatillada por magdalenas semejantes) y 'repetición' (la insistencia inarticulada de huellas traumáticas idénticas) en el ámbito de la experiencia contemporánea. La literatura contemporánea (de Kafka y Céline a Beckett y William Burroughs, o bien, en una serie hispanoamericana, de Arlt a Droguett, de Onetti a Bolaño y Fresán) elevaría la neurosis postraumática a un nuevo estándar, a una suerte de malestar privativo de nuestra época.

En cuanto a la discusión conceptual involucrada en esta nueva hegemonía de la repetición en la experiencia humana, es posible que Más allá del principio del placer (1920) sea el punto de partida más fuerte. Allí Freud sostuvo que la repetición operaba contra el principio homeostático (o principio de placer) del aparato psíquico, develando la existencia de una fuerza primordial y compulsiva que denominó 'pulsión de muerte'. Por medio de esa figura arriesgada Freud intentaba elaborar para su aparato homeostático algo del orden de la entropía termodinámica, una tendencia desreguladora que a la larga siempre consigue imponerse. Pero algo no cuadraba: aun cuando se percibía una desorganización a nivel orgánico y energético (sintomatología fisiológica y displacer) aquello que la provocaba no parecía participar del mismo nivel de realidad. ¿En qué nivel podrían situarse unas marcas repetitivas (palabras, imágenes, sonidos) que sin tocar la materia viviente, sin ejercer una fuerza mecánica sobre ella, se muestran capaces de dañarla y traumatizarla? La fuerza explicativa de la termodinámica se detenía frente a esa zona repetitiva y displacentera del aparato. En las últimas dos líneas de su ensayo Freud reconoce la insuficiencia de sus formulaciones: "Lo que no puede tomarse volando hay que alcanzarlo cojeando. / La escritura dice: no es pecado cojear" (Freud 62).

En el Libro 2 de su Seminario (1954-55) Jacques Lacan se propuso retomar desde ese punto trabado o cojo: intento un nuevo progreso para la teoría psicoanalítica que atenuaba el peso de la termodinámica freudiana, y ponía al analista sobre una pista cibernética. Se trataba de seguir de cerca ya no a aparatos dinámicos, sino a una nueva generación de máquinas capaces de procesar símbolos y autorregularse. En las primeras sesiones (IV y V) Lacan presenta una especie de relato de ciencia ficción que funciona como mito de origen del analista en tres momentos. Primer momento: todos los humanos han abandonado la Tierra; se han extinguido, o bien ya no tienen gran cosa 
que decir. Lacan no lo dice explícitamente pero no es difícil ver allí a viejos humanistas en retirada. Segundo momento: no queda sobre el planeta más que cascadas, lagos, montañas, rayos y truenos. Pero en lugar de recomenzar con Adán y Eva, o con un olimpo de dioses, Lacan ha dejado en calidad de testigos a un conjunto de máquinas cibernéticas capaces de comunicarse entre sí con señales, capaces de reconocer figuras básicas y de registrar eventos en cintas audiovisuales. Tercer momento: tras un largo ciclo los humanos retornan a un mundo dominado por inteligencias artificiales -tampoco es difícil interpretar que se trata de analistas-. Este encuentro-interrogación a la máquina será para Lacan un encuentro inédito con el registro simbólico en crudo, puesto que "el mundo de la máquina es el mundo simbólico" (77). Un mundo que opera a saltos y tumbos, con aberturas y cierres, unos y ceros. Los analistas cierran la jornada jugando 'pares e impares' con máquinas de Turing ${ }^{1}$. Pero en lugar de servirse de la técnica de identificación imaginaria que Poe sugirió para vencer contrincantes humanos, Lacan afirmará que en el mundo de la máquina será estrictamente necesario entrenarse en cálculo y estrategia simbólica.

Con este mito poshumanista sobre la caída del ego y sobre una nueva hegemonía de la estrategia simbólica, el psicoanálisis ofrecía su propia versión de la posguerra o del inicio de la guerra fría. Los analistas parecían especialmente preparados para enfrentar un período postraumático que Adorno definió en estética como 'alérgica contra lo expresivo' (Adorno 206), donde incluso los artistas se entrenaban en métodos aleatorios de composición para reducir o abolir la aparición de patrones demasiado humanos.

\section{LA DOBLE ENTROPÍA: E + I}

En la sesión VI Lacan afirmará que entre el pensamiento 'humanista' de un filósofo como Hegel y el pensamiento de Freud está la termodinámica. La primera formulación del psicoanálisis no es concebible sin un concepto cuantitativo de energía y sin un modelo capaz de dar cuenta de ganancias y pérdidas energéticas al interior de máquinas y turbinas. Análogamente, el mito sci-fi del analista lacaniano marcó una ruptura con Freud basándose en la aparición de la cibernética. El Libro 2 es un mandato respecto de la necesidad de estudiar los conceptos de las teorías de Claude Shannon y de Norbert Wiener, desarrolladas en Estados Unidos durante la Segunda Guerra Mundia y divulgadas desde fines de los $40^{2}$. Lacan lee y asimila tempranamente esos trabajos y expresa a sus discípulos que estaban frente a un 'alumbramiento' teórico mayor: una elaboración de las categorías puras del campo simbólico (sesión VII). Entre ellas la principal era un concepto matemático de infor mación (al que Lacan referirá indistintamente con una I mayúscula o una $F$

1 Se trata de un juego que Lacan retoma de La carta robada de Edgar Allan Poe: un jugador debía adivinar, poniéndose imaginariamente en el lugar del otro, si su contrincante ocultaba un número par o impar. En el caso de los analistas el juego será contra máquinas que escogen aleatoriamente sus números.

2 Refiero a tres publicaciones claves: The Mathematical Theory of Communication (1949) de Claude Shannon y Warren Weaver; Cybernetics: Or Control and Communication in the Animal and the Machine (1948) y The Human Use of Human beings (1950), ambos de Norbert Wiener. 
mayúscula): una medida que indica la probabilidad que tiene un mensaje de ser seleccionado dentro de un set de mensajes posibles, sin referencia alguna al problema del significado ${ }^{3}$. Este nuevo concepto permitía adicionalmente una segunda operación inédita: la posibilidad de medir su propia pérdida, pérdida de información o 'entropía cibernética'.

De acuerdo con Lacan lo que habría hecho cojear a Freud en Más allá del principio del placer fue precisamente la imposibilidad de ampliar el problema de la entropía termodinámica de su aparato al campo simbólico del significante: "sigue durante todo el artículo esa rondita infernal, como Diógenes buscando un hombre con su linterna. Le faltaba algo. Sería demasiado simple decirles -lo voy a decir- que bastaría con añadir una $F$ mayúscula o una I mayúscula a la E mayúscula" (130). Lacan aumentará la apuesta, y dejará resonando desde el 55 una poderosa advertencia-provocación que excede al auditorio psicoanalítico: "Es preciso iniciarlos a este sistema simbólico [i.e. uno que considera los conceptos cibernéticos] si quieren ustedes abordar órdenes enteros de una realidad que nos toca directamente. Quien no tenga idea del manejo correcto de esas $\mathrm{E}$ y esas $\mathrm{F}$ mayúsculas, puede no estar calificado para hablar de relaciones interhumanas" (131-32). El mensaje es rotundo: o se progresa en la nueva combinatoria de la $\mathrm{E}$ y la I, o se queda fuera de juego en el ámbito de las ciencias humanas contemporáneas.

El primer concepto, la E mayúscula, no era nada nuevo. Es la segunda ley de la termodinámica, la entropía 'clásica'. Cada trabajo del organismo implica una pérdida marginal de energía, que se traduce en un incremento calórico que desorganiza el sistema. A largo plazo ocurre siempre lo mismo: aleatorización, descomposición y muerte ${ }^{4}$. Los viejos humanistas conocían bien la E: la inmortalidad del autor consistía precisamente en salvarse del polvo. Lo nuevo estaba del lado de la I o $\mathrm{F}$ mayúscula: ¿a qué podría aludir la entropía en el campo de la información? Su discusión matemática y estadística es compleja; no está resuelta ni exenta de ambigüedades. Según Shannon la entropía será mayor en tanto más alto sea el grado de libertad o incertidumbre en la selección de mensajes. Un sistema con el máximo nivel de entropía coincidiría, ingenierilmente, con una producción máxima de información: selección estrictamente aleatoria de mensajes, lanzamiento de dados. El problema con esa definición es que desconoce el sentido de desorganización, pérdida y daño que estaba en el núcleo del concepto 3 En palabras de Shannon: "These semantic aspects of communication are irrelevant to from a set of possible messages" (Shannon 31). Yluego: "If the number of messages in the set is finite then this number... can be regarded as a measure of the information produced set is finite then this number... can be regarded as a measure of the information produced when one message is chosen from the set, all the choices being equally likely" (32). La la cantidad de información que el sistema puede producir. Mientras más homogénea la distribución probabilística de los símbolos mayor será la libertad de elección, mayor la incertidumbre, y por tanto mayor la cantidad de información involucrada en cada selección de mensaje.

4 En termodinámica 'muerte calórica' es el destino final de la materia: "Inevitably, by the second law, such systems must lapse into the state of totally unorganized, randomly distributed, inconvertible particles, the state of totally bound energy known -appropriately enough- as heat death" (Beniger 37). 
de entropía termodinámica. Y con ello el concepto pierde fuerza. Norbert Wiener, polemizando abiertamente con Shannon, optó por definir la información como forma que intenta resistir, por un tiempo siempre limitado, la tendencia natural hacia la desorganización. De modo que, al contrario de Shannon, una caída en la medida de información de un sistema equivaldría a un aumento de entropía.

Cuando Lacan retoma la entropía cibernética en el campo de la pulsión de muerte freudiana está más cerca de la posición de Wiener. Su apuesta consistió en considerar la repetición como una de las figuras claves para pensar en pérdidas y desorganizaciones de origen simbólico: ¿qué ocurre cuando ciertos significantes traumáticos comienzan a repetirse desnivelando la distribución probabilística del set pretraumático? Lacan añadirá que la tendencia o compulsión humana a la repetición es por sí misma una contribución a la entropía cibernética o simbólica. El Libro 2 no apunta apenas a describir cada una de las entropías por separado, sino a iniciarse en sus dialécticas conjuntas. Combinatorias de la $\mathrm{E}$ y la I. Esa es la dirección a la que apunta el concepto de 'circuito', introducido en la sesión VII: exige al analista pensar en lo humano como siempre ya integrado al sistema de envíos y reenvíos de mensajes propio del orden simbólico: "[e]l discurso del Otro es el discurso de circuito en el que Yo estoy integrado. Yo soy uno de sus eslabones" (89). E 'esquema $L$ ' es un circuito mínimo que reformula el aparato termodinámico freudiano en términos cibernéticos: hay un set de significantes ' $A$ ', y hay un mensaje ' $S$ ' (uno de los significantes del set) que circula por los eslabones del circuito ${ }^{5}$. El más pasivo de tales eslabones es el ego, que suele pasar el tiempo fascinado por las 'buenas formas' $\left(a^{\prime}\right)^{6}$, hasta que de pronto el mensaje ' $S$ ', que está siempre circulando y repitiéndose, entra en su esfera y le hace dar tumbos. En definitiva, cuando la repetición no ocurre en un set, sino en el organismo vivo lo que se produce es un compromiso entre repetición simbólica y pulsión; una zona mixta de información y fisiología que produce malestares y náuseas cibernéticas.

\section{EL CIRCUITO SEGÚN WILLIAM BURROUGHS}

Siguiendo a Lévi-Strauss, Fredric Jameson ha propuesto como tesis general que cada época presentaría sus propios enigmas de representación, referidos a ciertos conflictos fundamentales que las sociedades -incapaces o renuentes a resolver en lo real-intentan resolver simbólicamente en la organización formal de la obra de arte. En el ámbito de la literatura "the individual narrative, or the individual formal structure, is to be grasped as the imaginary [or formal] resolution of a real contradiction" (Jameson 77). El término 'enigma' se sostiene en cuanto refiere a contradicciones que no presentan un nivel de elaboración o codificación que permitiese representarlos como meros 'contenidos' en la obra. Al respecto, la propuesta central de este artículo consiste en sugerir que las combinatorias de entropía termodinámica

5 Aquellos ' $\mathrm{S}$ ' que interesan a Lacan son precisamente esos significantes iterativos que operan más allá del principio del placer -aquellos que entrelazan compulsión repetitiva (humana) y entropía cibernética-

6 En el Libro 2 "a" no equivale aún al 'objeto a', sino a una gestalt perceptiva: el buen cierre de una figura. 
(E) y entropía cibernética (I) -advertidas por Lacan desde el 55- apuntan precisamente a enigmas de ese tipo: no se trataría solo de un problema teórico mayor del psicoanálisis, sino asimismo de un enigma de representación clave para aquella literatura contemporánea que trata la repetición como figura dominante de la experiencia.

Así como Estados Unidos fue el epicentro del 'alumbramiento' cibernético, la narrativa norteamericana contemporánea parece ofrecer las formulaciones más sistemáticas en torno al enigma de la doble entropía?. Entre los autores claves William Burroughs es el más temprano y posiblemente el que definió con más precisión la pista a seguir. Su estrategia consistió en explotar cierto saber acumulado en el campo del broadcasting y de la publicidad. Allí ya habían dado con sus propias formulaciones y técnicas para tratar con esas marcas que sin tocar el cuerpo son capaces de traumatizarlo y engancharlo: golpes y capturas producidas on the air desde canales audiovisuales: 'hit songs', 'slogans', 'catchphrases'8. En The ticket that exploded (1962/67), novela central de su Trilogía Nova, Burroughs afirmará la existencia de un nuevo tipo de escritura-inscripción hegemónica que llamó 'escritura blanda'. Se trata de un circuito de canales audiovisuales administrados por corporaciones y sus aliados en la industria mediática que transmite y repite palabras, sonidos e imágenes que se inscriben como 'pistas' o 'tracks' en el cuerpo de los consumidores: "association lines come alive in your flesh" (206-7). El cuerpo es un 'ticket blando' entregado a inscripciones administradas: "thin transparent sheets on which is written the action from birth to death -Written on 'the soft typewriter'" (181). El resultado es carne enferma y adicta. La gran maquinaria de escritura blanda elaborada en la Trilogía Nova es una exploracion en la zona ambigua entre cuerpo y símbolo, consciente de su carácter pionero. Burroughs suele interrumpir avances herméticos con excursos didácticos: "any image repeated loses charge and that loss is the lack that makes this Hell and keeps us here" (214), y luego: "You see how we were caught in repetition sets?" (ibid.)

El plan de Burroughs fue aproximar tanto como fuera posible la escritura literaria a la lógica de la escritura blanda. Las marcas que le interesan no son las de una escritura que pueda ser leída serialmente, de izquierda a derecha, sino unas que aparecen en irrupciones, repeticiones, pulsaciones. Allí donde algo pulsa algo ha sido escrito en la carne. Para identificar los cortes o nudos de estas nuevas unidades Burroughs buscará, como Lacan,

\footnotetext{
7 Refiero cronológicamente a los siguientes autores: William Burroughs, Philip Dick,
Thomas Pynchon, Don Delillo, William Gibson y David Foster Wallace. Al respecto habría que considerar la posibilidad de que el enigma de la doble entropía esté estrechamente ligada a los modos de producción y consumo 'posindustrial' (de informacion y tecnologia) Coming Up of Post-Industrial Society: A Venture in Social Forecasting (1973)

8 En alemán, los términos equivalentes a 'catchphrase' ('stichwort') y a 'slogan' ('schlagwort') refieren literalmente a traumas de carácter mecánico (morder, acuchillar, golpear) en el campo de la información. Por su parte, la palabra inglesa 'catchphrase' enfatiza el gesto de atrapar ('catch'). Lo mismo 'broadcasting': 'cast' refiere al acto de lanzar un anzuelo, de modo que broadcasting tendría el sentido de lanzar un anzuelo hacia el espacio amplio esperando un enganche. Una variante del circuito de Lacan: cuerpos enganchados a un hilo que toma la forma de flujos audiovisuales que provienen de canales de información.
} 
respuestas en el cruce entre teoría de información y fisiología, llegando a la siguiente fórmula elemental: trátese de imágenes, sonidos o imágenes, la escritura blanda opera siempre en base a "sex and pain information" (201) Aquello que es del orden de la presencia (audiovisual) operará como pantalla o captura imaginaria que encubre una inscripción subliminal, un golpe que ocurre en otro nivel: una zona de contacto-fusión entre lo simbólico y lo fisiológico. Dar cuenta de esas marcas blandas que no son idénticas a la presencia audiovisual que las gatilla exige conceptos 'puros' de lo simbólico: p.e. el concepto cibernético de información. Pero a la vez Burroughs excederá esa pureza: el tipo de información que le interesa no es sobre sexo dolor, sino que es sexo y dolor (adicción y trauma). Un punto en que carne e información dejan de ser distinguibles: "Film flesh" (79). El punto en donde la $\mathrm{E}$ y la I se entrelazan sincronizando pulsaciones y degradaciones.

The Ticket that Exploded está organizada como una sucesión de escenas en donde los cuerpos son sometidos a sesiones intensivas y radicales de escritura blanda. El proceso será narrado como la entrada del sujeto a un parque de diversiones Ilamado Garden of Delights o simplemente G.O.D. Un fuerte enganche marca el ingreso: "you sit down anywhere some sex whee sidles up your ass or clamps onto your spine centers" (3-4). Lo que sigue será un recorrido veloz de desposesión en donde las palabras, imágenes y ruidos íntimos del cuerpo de la víctima son primero grabados y luego recombinados con pistas audiovisuales de cuerpos ajenos (de otras víctimas o de agentes entrenados), así como con viejas 'hit songs' y 'catchphrases' que ya estaban circulando por los canales. A la salida del recorrido lo único que queda son "muttering absent bodies hanged after being milked of identities" (115). El Jardín de las Delicias es una variante del circuito lacaniano en la forma de sesiones de tortura audiovisual, estimulación erógena y desorganización subjetiva. Burroughs apuntará adicionalmente a cierto 'goce del circuito'10 uno que parece crecer y alimentarse de las pérdidas propias de la doble entropía - a costa de sujetos drenados ${ }^{11}$

\section{EL INFIERNO TAN TEMIDO DE ONETTI}

A partir del tipo de 'soluciones simbólicas' que Burroughs muestra en alto grado de elaboración se abre un interesante proyecto crítico que consistiría en volver o replegarse sobre aquellos momentos en donde algo del orden de la doble entropía se insinúa; allí donde el escritor contemporáneo tantea los nuevos enganches de la $\mathrm{E}$ y la I, entre traumas e insomnios cibernéticos. Aquí me limitaré a mostrar un último caso, uno hispanoamericano, para indicar

9 No extraña que para Burroughs el porno y los films de tortura sean la verseión más eficaz de escritura blanda.

10 Debo esa fórmula a los comentarios de Esteban Radiszcz sobre la ponencia que dio origen a este artículo, durante el "Coloquio de Literatura, Psicoanálisis y Cultuwra" ( $8 /$ Mayo/2014).

11 En definitiva, una teoría de la escritura blanda exige alta complejidad conceptual pero Burroughs apostó a que se trataba de un fenómeno a tal punto constitutivo de la experiencia contemporánea que podía considerarse autoevidente: "You understand sex and pain information so why ask questions?" (201). La extravagancia de sus elaboraciones no impidió su masificación y el rostro de Burroughs quedó en el centro de la carátula de Sgt. Pepper's Lonely Hearts Clubs Band entre los íconos del siglo. 
que las posibilidades de este campo de estudio no se limitan a la narrativa norteamericana contemporánea ni a las discusiones postraumáticas de la posguerra europea.

El infierno tan temido (1959) de Juan Carlos Onetti nos presenta la procesión de un empleado periodístico en la ciudad de Santa María. Risso terminaba de redactar una nota sobre hípica cuando recibe un sobre con una fotografía: "[e]n la fotografía la mujer sin cabeza clavaba ostentosamente los talones en un borde de diván, aguardaba la impaciencia del hombre oscuro, agigantado por el inevitable primer plano" (216). En el reverso de la imagen se leía 'recuerdos de Bahía' con la manuscritura de Gracia, su ex esposa. Será la primera de una serie de fotografías -enviadas luego desde Lima, Santiago, Buenos Aires, Rio y Montevideo- en las que ella aparecerá siempre debajo de un nuevo hombre. Risso intentará resguardarse de este bombardeo de mensajes "como una bestia que oyera rebotar los tiros de los cazadores en la puerta de su cueva" (222). La mucama consigue de todos modos despachar una nueva carta que Risso verá vibrar desde su escondite: "vio colgar el sobre de las tablillas de la persiana, comenzó a percibir cómo destilaba en la penumbra, en el aire sucio, su condición nociva, su vibrátil amenaza" (218). Luego será un colega, el viejo Lanza, quien le hará llegar otro sobre con la nota "para ser donada a la colección Risso" (224), comentándole de paso cuán sórdido le parecía el jueguito de Gracia.

El infierno tan temido es la versión mínima del parque de torturas audiovisuales de Burroughs. La creciente redundancia de 'información de sexo y dolor' producirá entropía: "en el plano mágico en que habían empezado a entenderse y a dialogar, Gracia estaba obligada a enterarse de que él iba a romper las fotos apenas llegaran, cada vez con menos curiosidad, con menor remordimiento" (218). Pero esa pérdida (pérdida de información, pérdida de afecto) provocará en Risso un aumento de malestar. Intentará desengancharse por extravagantes vías imaginarias. En medio de su peor insomnio, tras destruir otra foto de Gracia, le sobreviene una paz reconciliatoria: "la comprensión ocurría en él, liberada de la voluntad y la inteligencia" (225); las lágrimas le caían por la cara, y comenzó a tener visiones, "[v]eía la muerte y la amistad con la muerte" (ibid.), hasta que por fin "lo invadió por primera vez un paternal cariño hacia los hombres y hacia lo que los hombres habían hecho y construido" (ibid.). Al día siguiente se suicida. El relato se cierra con las palabras del viejo Lanza culpando a Risso de su destino: "[p]orque en ningún momento llamó yegua a la yegua que estuvo repartiendo las soeces fotografías por toda la ciudad, y ni siquiera aceptó caminar por el puente que yo le tendía, insinuando, sin creerla, la posibilidad de que la yegua - en cueros y alzada como prefirió divulgarse... estuviera loca de atar" (226).

Onetti comentó en entrevista $A$ fondo con Soler Serrano que El infierno tan temido está basado en una anécdota real de una pareja de empleados de radio. Intentó escribirla varias veces pero solo se sintió satisfecho cuando la escribió como historia de amor, bajo la premisa de que los envíos de Gracia indicaban que seguía enamorada. Ahora, no es sencillo determinar qué tipo de mensaje amoroso puede ser una foto porno de la amada circulando por canales de información. Lo que hace Onetti es situarnos tempranamente sobre la pista del porno como 'vía regia' hacia la zona dual de las entropías. Como 
el broadcasting el porno tiene su propio modo elemental de referir a nuestro enigma: dialécticas de lo duro (hardcore) y lo blando (softcore). Lo blando será aquello repetitivo que no degrada suficientemente las formas queridas, que no trauma lo suficiente ni conduce a insomnios postraumáticos. Lo duro, hardcore, snuff movies, sí que lo consigue. Un ego aturdido en el terminal pasivo del circuito padece la blandura o dureza de inscripciones subliminales. En definitiva, cuando las formas queridas del ego transitan por los circuitos de doble entropía, cuando la alteridad en juego es antes el circuito (G.O.D.) que el otro amado, las reacciones imaginarias participan ya de un malestar cuyo reverso es goce del circuito. Es el álgebra de las relaciones humanas en una escena dominada por fugas cibernéticas. En contrapunto al analista, los circuitos macabros del escritor contemporáneo expresan incomodidad respecto de vías estratégicas (puras) que exigen una caída excesiva del imaginario y de su rol clave en el campo estético. Son recorridos que exploran esa zona incierta en que podría elaborarse algo del orden de la reconciliación para quien está ya integrado y aturdido en el circuito. 
